\title{
A case of oculomotor nerve palsy associated with antimitotic spindle apparatus
}

This article was published in the following Dove Press journal:

Clinical Ophthalmology

26 April 20I I

Number of times this article has been viewed

Jong Jin Jung

Ungsoo Samuel Kim

Department of Ophthalmology, Kim's Eye Hospital, Konyang University College of Medicine, Seoul, Korea
Correspondence: Ungsoo Samuel Kim Department of Ophthalmology,

Kim's Eye Hospital, Konyang University College of Medicine, Youngdeungpo 4th 156, Youngdeungpo-gu, Seoul, 150-034 Korea

Tel +822 26397777

Fax +822 26779214

Email ungsookim@kimeye.com
Abstract: In this case report, we describe a case of isolated oculomotor nerve palsy associated with antibodies to mitotic spindle apparatus (anti-MSA). A 28-year-old female patient had acute, painful vertical diplopia. She had limited depression and adduction in the right eye. There was no relative afferent pupillary defect. Brain magnetic resonance imaging showed no abnormal findings. Laboratory tests were all negative, with the exception of positive anti-MSA, She had an excellent and rapid response to treatment with corticosteroids, and completely recovered after two weeks of steroid pulse therapy.

Keywords: antibodies, mitotic spindle apparatus, autoimmune disease, third nerve palsy

\section{Introduction}

The causes of isolated oculomotor nerve palsy have been documented in various diseases. Most cases of isolated third nerve palsy are attributable to disease states that affect the vascular system, including diabetes mellitus and hypertension. ${ }^{1}$ However, we must carefully consider other causes in young patients without vasculopathic risk factors. Multiple sclerosis, Sjogren's syndrome, antiphospholipid syndrome, and leukemia involving the central nervous system are rarely reported as causes of isolated oculomotor nerve palsy, ${ }^{2,3}$ but oculomotor nerve palsy associated with antibodies to mitotic spindle apparatus (anti-MSA, an auto-antinuclear antibody) has not been reported to date. We describe a patient with isolated oculomotor nerve palsy associated with anti-MSA.

\section{Case report}

A 28-year-old woman suddenly developed painful vertical diplopia. She had been suffering from a cold for one week. She had no significant contributory past history and no systemic diseases, such as diabetes mellitus, hypertension, or coagulopathy. A full ophthalmologic examination was performed. Her best corrected visual acuities were 20/25 in the right eye and 20/30 in the left eye. Alternate cover prism test revealed 10 prism diopters of hypertropia in the right eye. She had limited depression and adduction in the right eye as well (Figure 1). The forced duction test was negative. There was no relative afferent pupillary defect.

We performed laboratory tests, including a complete blood cell count, erythrocyte sedimentation rate, C-reactive protein, rheumatoid factor, antinuclear antibodies, antineutrophil cytoplasm antibodies, and serologic tests for viral markers. We also performed a chest $\mathrm{x}$-ray and brain magnetic resonance imaging. The laboratory 


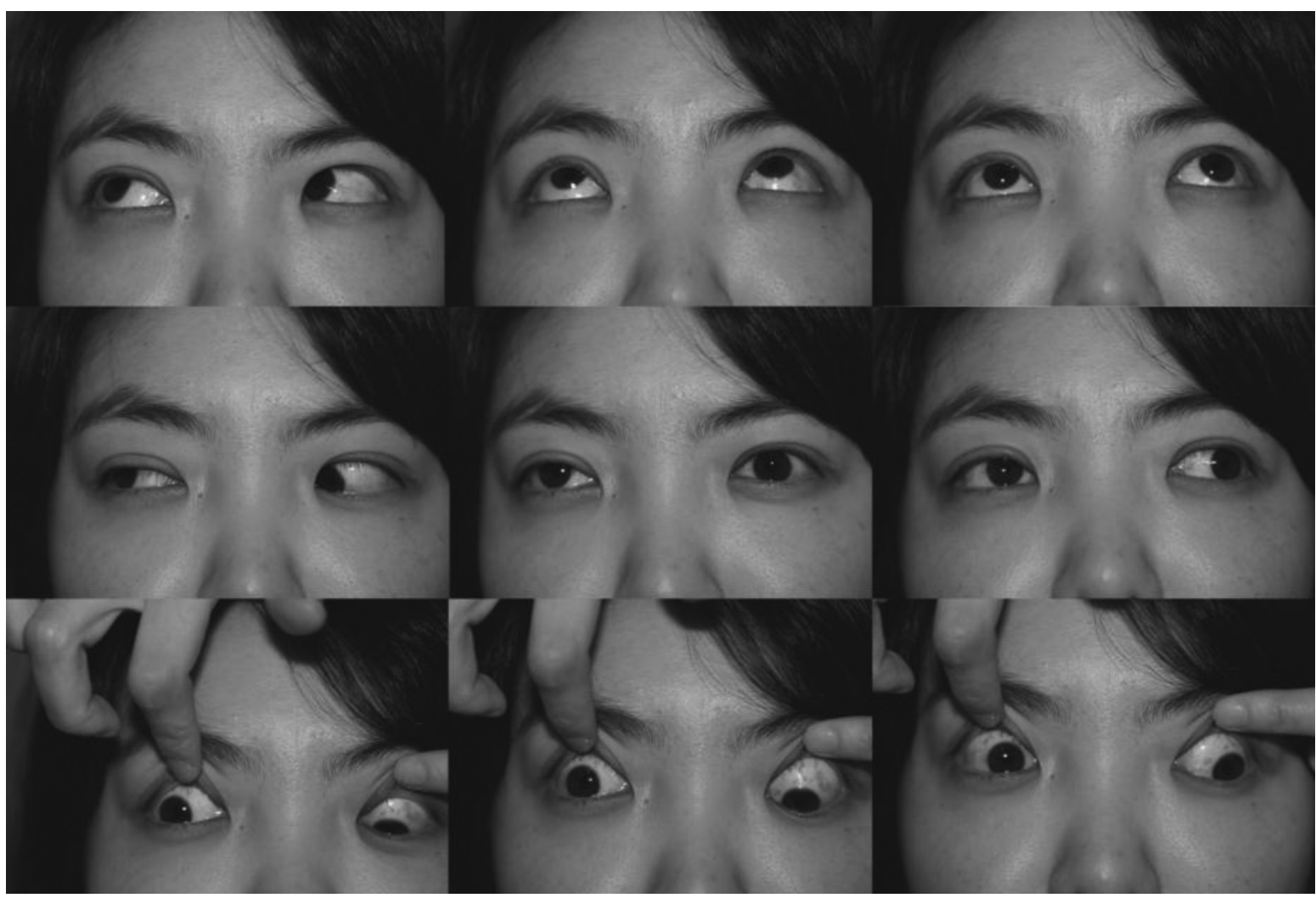

Figure I Nine cardinal directions of gaze showing exodeviation, limitation of adduction, and infraduction in the right eye at initial visit.

findings were unremarkable, with the exception of positive rheumatoid factor (titer 1:320) and antinuclear antibody (mitotic spindle fiber type, titer 1:620). Brain magnetic resonance imaging with gadolinium enhancement revealed no abnormal findings.

We believed that the patient had pupil-sparing incomplete third nerve palsy (mainly involving the inferior division) related to autoimmune disease, so admitted her and treated her with intravenous methylprednisolone $250 \mathrm{mg}$ four times daily for three days, and tapered the steroid thereafter. Her extraocular movements resolved completely at two weeks after steroid pulse therapy. The last follow-up visit was performed six weeks after the initiation of steroid pulse therapy. During the follow-up period, she manifested no significant neurological sequelae.

\section{Discussion}

Anti-MSA antibodies are not associated with a defined autoimmune pathology, but some studies have reported anti-MSA in the sera of patients with connective tissue diseases, infections, autoimmune hepatitis, vasculitis, primary antiphospholipid syndrome, malignancy, and fever of unknown origin. ${ }^{4,5}$ The aforementioned autoimmune diseases are well associated with oculomotor nerve palsy. However, the present report is the first reported case of a patient with isolated oculomotor nerve palsy associated with anti-MSA. The mitotic spindle apparatus is a unique structure of microtubules and associated proteins involved in the segregation and reorganization of chromosomes during cell division. Anti-MSA is identified during the immunofluorescent detection of antinuclear antibodies, which are associated with autoimmune diseases. ${ }^{6,7}$

There are two possible mechanisms related to this cranial neuropathy with autoimmune diseases, namely "vascular" (due to damage of the vasa nervorum) or an "immunologic cause" (due to lymphocytic infiltration of the nerve). ${ }^{8}$ The patient had an excellent and rapid response to intravenous methylprednisolone treatment and completely recovered two weeks after the start of steroid pulse therapy. Therefore, lymphocytic infiltration or autoantibodies to components of the cranial nerves might play an important role. Lui et $\mathrm{al}^{2}$ also reported on a patient with unilateral oculomotor nerve palsy and Sjogren's syndrome who experienced an almost complete recovery of both ptosis and diplopia after two weeks of treatment, and an immunologic neuropathic process was thought to be the cause.

In conclusion, although oculomotor nerve paralysis is usually believed to be self-limiting, steroid pulse therapy should be considered in cases of ocular paralysis when 
other possible causes, such as autoimmune disease, have been excluded.

\section{Disclosure}

The authors have no financial conflict of interest to declare regarding the subject matter of this manuscript.

\section{References}

1. Greco D, Gambina F, Maggio F. Ophthalmoplegia in diabetes mellitus: A retrospective study. Acta Diabetol. 2009;46:23-26.

2. Lui NL, See SJ, Thumboo J. A rare cause of reversible unilateral third nerve palsy. J Neurol Sci. 2008;275(1-2):188-190.

3. Champion BL, Choy F, Schrieber L, et al. Isolated fascicular oculomotor nerve palsy as the initial presentation of the antiphospholipid syndrome. J Clin Neurosci. 2002;9:691-694.
4. Celebisoy N, Bayam FE, Cağirgan S, et al. Primary central nervous system leukemia presenting with an isolated oculomotor palsy. J Clin Neurosci. 2008;15:1144-1145.

5. Bonaci NB, Andrejevic S, Bukilica M, et al. Autoantibodies to mitotic apparatus: Association with other autoantibodies and their clinical significance. J Clin Immunol. 2006;26:438-446.

6. Limaye V, Roberts-TP, Gillis D, et al. The clinical associations of mitotic spindle autoantibodies in a South Australian cohort. Aust N Z J Med. 1999;29:713-717.

7. Mozo L, Gutiérrez C, Gómez J. Antibodies to mitotic spindle apparatus: Clinical significance of NuMA and HsEg 5 autoantibodies. J Clin Immunol. 2008;28:285-290.

8. Galbussera A, Tremolizzo L, Tagliabue E, et al. Third cranial nerve palsy? Look for a sicca syndrome. J Neurol Sci. 2007;253:88-89.
Clinical Ophthalmology

\section{Publish your work in this journal}

Clinical Ophthalmology is an international, peer-reviewed journal covering all subspecialties within ophthalmology. Key topics include: Optometry; Visual science; Pharmacology and drug therapy in eye diseases; Basic Sciences; Primary and Secondary eye care; Patient Safety and Quality of Care Improvements. This journal is indexed on

Submit your manuscript here: http://www.dovepress.com/clinical-ophthalmology-journal

\section{Dovepress}

PubMed Central and CAS, and is the official journal of The Society of Clinical Ophthalmology (SCO). The manuscript management system is completely online and includes a very quick and fair peer-review system, which is all easy to use. Visit http://www.dovepress.com/ testimonials.php to read real quotes from published authors. 